\title{
UM FINAL DE SEMANA NO ZOOLÓGICO: UM PASSEIO EDUCATIVO?
}

\section{A WEEKEND IN THE ZOO: AN EDUCATIVE TRIP?}

\author{
Dra.Silvania Sousa do Nascimento \\ Departamento de Métodos e Técnicas de Ensino FAE- UFMG \\ Cristiana Batista Costa \\ Instituto de Ciências Biológicas da Universidade Federal de Minas Gerais
}

\section{RESUMO}

Os museus abertos, como parques e zoológicos, exercem um papel importante na divulgação e na popularização das ciências. Eles, geralmente, propõem atividades dirigidas ao grande público heterogêneo constituído de uma parcela considerável de grupos familiares. As atividades educativas oferecidas nesses espaços induzem diferentes níveis de interatividade entre os visitantes e os animais. Nosso artigo resume a observação de quatro grupos familiares no borboletário da Fundação Zoo-Botânica de Belo Horizonte, resultando em dados que foram avaliados qualitativamente. O resultado indica três níveis de interatividade entre os elementos de exposição desse espaço e os integrantes do grupo.

Palavras chaves : museus, zoológicos, interatividade, grupos familiares.

\begin{abstract}
"Open museums", as parks and zoos, have an important role in the popularisation of sciences. They, generally, propose activities addressed to a heterogeneous public, constituted of a considerable portion of family groups. The educational activities offered in those museums induce different interactivity levels between the visitors and the exposed objects. Our paper summarizes the observations of four family groups in the butterfly's gate of the Zoo-Botanical Foundation of Belo Horizonte, resulting in data that were examined qualitatively. The results indicate three interactivity levels between the elements of the exhibition and the members of the group.
\end{abstract}

Keys words: museums, zoo, interactivity, family groups. 


\section{1 - INTRODUÇÃO}

No Brasil, ao contrário de diversos países europeus e americanos, é recente a pesquisa sobre os espaços de educação não-formal. Espaços públicos como parques, zoológicos, reservas naturais, sítios históricos, planetários oferecem ao visitante concomitante ao seu tempo de lazer, múltiplas atividades que, na maioria da vezes, estão relacionadas à preservação e à dimensão contemplativa do patrimônio. Destituídas de formalidade de cunho didático-pedagógico, as atividades ofertadas em um museu aberto enfocam problemas relacionados tanto à conservação do ambiente quanto a mudanças de comportamentos visando a melhoria da qualidade de vida do cidadão e a tomada de consciência das atitudes, positivas e/ou negativas, que influenciam na sua existência e na sua interação com o restante da sociedade. Nesses espaços não há imposição de regras ou normas que formalizem tais atividades como ocorre nas escolas, ainda que implicitamente os museus abertos possuam uma intenção de contribuir com o processo cognitivo do visitante. Observamos uma crescente discussão sobre a participação de espaços de educação não formal na produção e difusão do conhecimento e, consequentemente, na ampliação da cultura no cidadão.

Nosso estudo foi desenvolvido na Fundação Zoobotânica de Belo Horizonte (FZB-BH), entidade mantida pela prefeitura de Belo Horizonte que de forma contínua participa de programas de Educação Ambiental da cidade. Os resultados que discutimos aqui estão restritos ao borboletário da FZB-BH, o primeiro aberto ao público no Brasil. O objetivo da mesma consiste em compreender os diferentes níveis de interatividade entre os grupos familiares e os objetos ali presentes. Cada vez mais procurado como área de lazer, o zoológico representa também uma fonte de conhecimento e uma ponte de ligação estreita entre o homem, a natureza e a ciência. Segundo a Sociedade dos Zoológicos do Brasil, em estatística do ano 2000, 91 zoológicos brasileiros são responsáveis pela manutenção de cerca de 40 mil animais silvestres em cativeiro, em sua grande maioria da fauna nativa. Locais de conservação ex situ da diversidade biológica, os zoológicos dos grandes centros urbanos mantém em cativeiros espécies da fauna e flora nativa da região (cidade, estado, país), assim como espécies estrangeiras. Eles, entretanto, não se limitam apenas a guardar animais, são também, centros de formação, de pesquisa e de lazer. Eles exercem uma importantes de manejo de animais ameaçados de extinção e atuam na formação de grupos reprodutivos na tentativa de dar continuidade a essas espécies o que exige um esforço conjugado de pesquisas nas áreas de biologia, veterinária, ecologia e educação ambiental.

Enquanto espaços de lazer e cultura, os zoológicos são escolhidos por pessoas pertencentes a todos os grupos sociais. Famílias, estudantes, aposentados, portadores de necessidades especiais e visitantes solitários encontram no zoológico um lugar de agradável contemplação e prazer que lhes sacia a curiosidade em torno de animais e vegetais.

O borboletário atrai a atenção de inúmeros visitantes que passeiam pelas alamedas do zoológico, pois a beleza e o mistério que envolve cada fase da vida das borboletas e mariposas fascinam e excitam a curiosidade do público. Entretanto a interatividade entre o público e estes animais é pouco conhecida. Segundo Speziali \& Vaz (2000), as pessoas sentem necessidade de visitar o zoológico pela simples curiosidade em ver os animais, o que lhes dá prazer, sendo 
essa uma necessidade não intelectual. Porém o zoológico pode ir além concretização desse desejo e atuar na popularização da ciência e fornecer um forma de mediação alternativa entre o conhecimento científico e os diferentes saberes do visitante. A dinâmica da apresentação dos animais, plantas, objetos e fenômenos nos espaços de educação não-formal necessita de um formato que favoreça a exploração desses diferentes saberes do visitante, oferecendo-lhe oportunidade de ampliar seu conhecimento sobre as plantas e animais. A organização do espaços de exposição e dos recintos necessita orientar a ação sobre o objeto e tornar essa prazerosa aumentando, assim, o envolvimento, a motivação e a curiosidade. Esta ação será tanto mais efetiva quanto mais evidente for, para o visitante, a dinâmica da exposição. A organização e ocupação do espaço possibilita, de certo modo, uma leitura e pode ter a intenção de desafiar, assim como, dialogar com os saberes do visitante. Para a flexibilização da exploração das informações é necessário a utilização de formas de linguagem diversas: gestual, visual, oral, escrita. Esta flexibilidade assim como a liberdade de ação do visitante abrem a possibilidade de divergências na interpretação daquilo que é exposto. A possibilidade de estabelecer um diálogo entre os objetos expostos e o visitante é uma das grandes dificuldades para a apropriação de conhecimento em museus de ciências.

Os zoológicos permitem experiências multisensoriais aos visitantes e possuem como freqüentadores assíduos os grupos familiares. Consideramos um grupo familiar uma unidade multigeracional nuclear ( constituída de pais e filhos e/ou enteados) onde existem laços consangüíneos (avós, netos, tios, sobrinhos, primos). Para limitação do objeto de pesquisa, os grupos estudados foram restritos à composição máxima de seis membros sendo no mínimo um adulto de mais de dezoito anos e uma criança entre cinco e dez anos totalizando quatro estudos de casos.

\section{A INTERATIVIDADE NO ZOOLÓGICO}

A necessidade de estudar os espaços não escolares de lazer e de cultura, acrescentando aos aspectos comportamentais aqueles sobre o processo sócio-cognitivo, vem sendo destacada por pesquisadores de diferentes abordagens sociológica, psicológica ou pedagógica. Apesar da necessidade de se obter resultados de ordem prática e de diferenciação inter-grupo, a pesquisa atual aspira fornecer um quadro teórico e metodológico de análise das práticas educativas dos espaços não escolares. Uma abordagem comportamentalista restrita, limita o "ato da visita" à aquisição temporal de conceitos sem levar em conta noções como interação, apropriação e criação de significado. Por outro lado, uma abordagem sóciointeracionista considera o ato de visita desde o momento onde o grupo escolhe uma opção de lazer até o retorno ao lar e as lembranças da visita alguns dias, semanas ou meses depois. Destacamos o ato de visita como uma composição de saberes em ato que, como textos, necessitam ser codificados, lidos e compreendidos na cena de sua realização.

Há uma tendência mundial de estimular o visitante de museus de ciências a manipular diretamente os objetos. Esta tendência se justifica pela expectativa de que a ação direta entre 0 visitante e o objeto exposto leve à motivação intrínseca, estimulada pelo prazer, fazendo com 
que o visitante retorne freqüentemente a esse espaço. Entretanto, como em nosso estudo, nem sempre é possível uma manipulação direta com o animal, planta ou objeto de exposição, mas mesmo uma relação distanciada poderá despertar a curiosidade dos visitantes.

A interatividade é, em geral, definida como a ação recíproca entre dois ou mais elementos ou entre dois ou mais indivíduos, implicando em transferência simultânea e mútua de informações. Ampliando as perspectivas intra-individuais como a estruturalista e a cognitivista, para a análise do processo de construção de conhecimento, nós destacamos os aspectos interindividuais. A tese defendida por Vygotsky (1937) apresenta o caracter socialmente mediatizado das funções mentais superiores (atenção, memória, vontade, cognição) próprios dos seres humanos. Estas funções são intimamente ligadas a ação exterior (sobre o objeto) ou interior (psicológica). Por sua vez, as ações são estruturadas, instrumentalizadas e transformadas por procedimentos ou ferramentas socialmente elaboradas, tais como: a linguagem e outros signos verbais e não verbais que representam as relações entre os objetos, suas propriedades e os fenômenos observados. Segundo Vygotsky e outros que dão continuidade ao seu projeto de pesquisa, é o mecanismo de apropriação dessas ferramentas sócio-culturais que marcam essencialmente o processo de desenvolvimento cognitivo do indivíduo. Neste contexto, a análise do ato da visita representa o acompanhamento das interações sociais dos visitantes e suas ações sobre os objetos. Embora o lazer e o prazer sejam importante nessas situações, se acontece uma ação sobre os objetos, a mobilização pelo visitante de suas ferramentas sócioculturais para entender e/ou relacionar as informações apresentadas nos objetos pode culminar em processo de aprendizagem.

Dierking \& Falk (1994) observaram que a interatividade em grupos familiares ocorre preferencialmente internamente entre os membros das famílias. As crianças tendem a compartilhar informações descritivas sobre o objetos e os fenômenos observados, enquanto que os adultos buscam estabelecer relações entre estes, a leitura de legendas e saberes de natureza diversa. O papel destes saberes compartilhados pelo grupo familiar foi considerado, pelos pesquisadores, uma importante variável do comportamento dos grupos em espaços de educação não-formal. De fato, as trocas discursivas observadas tendem a envolver associações e comparações com eventos e informações passadas. A possibilidade de analisar este processo de aprendizagem implica, segundo Borum et al (1995), além da análise da aquisição de informações durante a interação do visitante com os objetos, a avaliação das conexões que os membros do grupo fazem com estes saberes.

Os objetos não estão mudos no contexto do museu, eles possibilitam diferentes níveis de interatividade entre o visitante, seu grupo e sua cultura. Consequentemente, a análise do ato da visita limitada a um modelo de estímulo versus resposta ou ação versus recepção oculta um diálogo silencioso entre os atores das ações e os objetos. Certamente um museu representa um sítio comportamental onde regras e normas sócio-culturais determinam alguns comportamentos e privilegiam alguns níveis de interatividade. O primeiro destes, visa catalisar a atenção do visitante no sentido da sensibilização de características físicas e estéticas do objeto. Para isso, os espaços não escolares têm privilegiado a observação passiva dos objetos. Nomeamos este nível de interatividade contemplativa. A manipulação vem em oposição à contemplação, desencadeando no visitante um comportamento ativo com relação ao objeto 
exposto. Na literatura anglo-saxônica estas situações são denominadas de hands on, onde o visitante manipula, toca, cheira e experimenta o objeto. Nós preferimos usar o termo de interatividade direta para este tipo de manipulação que há nos espaços museais.

Nestes dois níveis, tratamos a relação do visitante com objetos temporalmente presentes, ainda que de maneira virtual. Contudo, existem os objetos ausentes, presos na memória do visitante, aqueles que são acessíveis através de uma interatividade reflexiva. $\mathrm{Na}$ literatura algumas vezes este tipo de interatividade é chamada de minds on. O visitante dialoga com os objetos e fenômenos questionando e relacionando sua ação presente ou passada.

\section{3 - METODOLOGIA}

Nossa pesquisa utilizou basicamente dois instrumentos de coleta de dados desenvolvidos pela equipe PISEC: entrevista semi-diretiva anterior e posterior ao ato da visita e observação direta guiada por uma planilha comportamental.

Escolhemos aleatoriamente na fila de espera para entrada no borboletário, os grupos familiares que continham, no máximo, seis pessoas com pelo menos uma criança entre cinco e dez anos de idade e um adulto de mais de dezoito anos. Além das famílias nucleares formadas por pais e seus filhos foram observados grupos compostos por tios, sobrinhos e primos. Desde que obtínhamos a autorização para o acompanhamento da visita, era iniciada a coleta de dados. Foram pesquisados quatro grupos, identificados por letras, sendo duas famílias nucleares e duas famílias cujos membros tinham relações de parentesco consangüíneo (tios e sobrinhos). A entrevista semi-diretiva anterior e posterior à visita, possuía um roteiro de quatro questões dirigidas a todos os membros da família. A entrevista anterior visava a caracterização do grupo, motivação para a visita e questões sobre borboletas e mariposas. Ao final da visita as questões foram relacionadas ao ato de visita do grupo ao borboletário. As entrevistas foram gravadas e posteriormente transcritas para uma análise qualitativa dos dados.

A observação do comportamento e da interatividade dos grupos, no interior do borboletário, ocorreu em duas etapas: a primeira etapa no auditório do borboletário, onde um monitor proferia uma palestra de apresentação geral da biologia de lepdópteros (borboletas e mariposas) e a segunda, dentro do viveiro do borboletário, enquanto os grupos transitavam livremente. Os dados foram coletados em planilhas específicas para cada ambiente e cada grupo, e foram registrados de forma binária os comportamentos, e interatividade dos atores.

Das quatorze pessoas entrevistadas, nove eram do sexo feminino com idades variando entre 10 e 36 anos e cinco eram do sexo masculino cujas idades variavam de 5 a 40 anos. Foram entrevistados então: três crianças, cinco adolescentes, e seis adultos (cf. tabela 1 - ver pag. 15). O nível de escolaridade mais freqüente na pesquisa foi: Ensino Fundamental (seis pessoas), seguido pelo Ensino Médio (cinco pessoas), Ensino Superior (duas pessoas) e Educação Infantil (uma criança de 5 anos). 


\section{4 - DISCUSSÃO DOS RESULTADOS}

Nossa investigação teve um caracter exploratório, assim, optamos por uma pequena amostra que gerou dados para uma análise qualitativa. Inicialmente discutiremos as entrevistas e, posteriormente, a análise da observação direta do ato de visita.

As respostas representam a contribuição espontânea dos membros dos grupos sendo esperada a ausência de respostas por parte das crianças. Foi feito o registro à medida em que os entrevistados respondiam as questões abertas. Os dados obtidos, dos quatro grupos familiares, são apresentados a seguir numa estrutura modificada do questionário. $\mathrm{Na}$ análise destacamos a interatividade dos membros dos grupos e os elementos do recinto. Para facilitar a leitura introduzimos nomes fictícios aos entrevistados, preservando a linguagem oral das respostas.

Mas o que é um borboletário para os visitantes? Todos eles visitavam o borboletário pela primeira vez e souberam de sua existência durante o passeio ao zoológico. Os entrevistados declararam não saber o que é um borboletário, mas acreditam que é um local onde existem borboletas, como um recinto. Alguns acrescentaram que é o local onde se pesquisa sobre as borboletas ou um recinto reservado à reprodução das mesmas. Na entrevista coletiva notamos o diálogo interno ao grupo familiar, onde as crianças mais novas repetem as falas dos mais velhos como nos trechos mostrados a seguir.

\section{Grupo A}

Lugar onde cria borboleta. (Lea, 15 anos)

Lugar onde tem borboleta. (Leo, 12 anos)

Grupo B

Onde ficam as borboletas, as flores/ não sei não! (João, 9 anos)

Onde ficam as borboletas, onde se reproduzem, onde fazem estudo. (Paulo, 39 anos)

Flor! (Pedro, 5 anos)

Grupo C

Onde se ensina, mostra ao visitante metamorfose, larva, casulo, borboleta/ exposição de várias espécies. (Ronaldo, 40 anos)

Lugar onde criam borboletas e ensinam como elas nascem.(Mia, 10 anos )

Grupo D

Não faço a mínima idéia. (Alice, 12 anos)

Um cativeiro de borboletas. (Núbia, 20 anos)

Observa-se que a referência às borboletas está presente em quase todas as falas dos entrevistados antes da visita enquanto que nenhuma sobre às mariposas. Pode-se supor que esta presença decorre da denominação dada ao recinto - "borboletário" - bastante sugestiva ! Será que podemos concluir o mesmo para as declarações dos dois adolescentes do Grupo A e do adulto do Grupo $D$, ao darem respostas tão categóricas sem discorrerem mais sobre 0 assunto?

As duas crianças do Grupo B citaram flor em suas respostas. João, apesar da negativa ao final de sua resposta, demonstra indício de um saber cotidiano e mesmo mediatizado sobre 
borboletas e seu comportamento. Enquanto Pedro repete o que Ihe sugere significado: Flor! Paulo, o adulto deste grupo, busca expor um saber escolarizado sobre o assunto: local para reprodução e estudos de borboletas.

No Grupo $C$, Ronaldo e Mia relacionam o borboletário com o que poderíamos chamar de função educativa assim como Paulo, do Grupo B. Observamos na fala de Ronaldo, traços de um saber escolar ao descrever as fases da metamorfose das borboletas.

Ao saírem do borboletário perguntamos aos grupos o que eles viram no viveiro.

Grupo A

Eu vi muitas borboletas / vários tipos de borboletas/ diferente / várias cores /// Vi também o lugar pra elas comer, as fruta/// chupar os néctar /// foram várias borboletas, pronto. (Lea, 15 anos)

Eu vi/ várias plantas, borboletas de vários tipos, borboletas recém-nascidas. ( Leo, 12 anos)

Eu vi borboletas, as formas que elas se alimentam, vários tipos /// elas se alimentam basicamente de flores e frutos. (Mara, 36 anos)

Vários tipos de plantas/// De acordo com, as alimentações variadas. (Mônica, 21 anos)

Elas têm de vários tamanhos, várias cores e cada um come uma planta. (Lea, 15 anos)

Grupo B

Borboletas, flores/ frutas ///e mariposas. (Pedro, 5 anos)

Mariposas com olho/ variadas, todos os tamanhos /// são bem inofensivas. (Paulo, 39 anos)

\section{Grupo C}

Informações referente ao nascimento/ o ovo, pra/l/ larva, pro//l casulo e borboleta novamente. (Ronaldo, 40 anos)

Como é que nasce, o casulo e tudo. (Mia, 10 anos)

Grupo D

Muitas borboletas! Cada uma diferente da outra. ( Alice, 12 anos)

Os ovos delas/ quando ela se transforma em largatas/// se transforma em borboleta/// eu vi borboleta, vi plantas/// vi do que/// elas se alimentam/// os ovos/// os casulos. (Cléo, 12 anos)

Eu vi os casulos, as borboletas, as mariposas. (Núbia, 20 anos)

Após a visita, os entrevistados descrevem o cenário destacando o ciclo reprodutivo dos insetos e a referência apresentada pelo monitor sobre a alimentação das borboletas. Aparece pela primeira vez a palavra mariposa. Na entrevista perguntamos como os visitantes diferenciam os dois insetos.

Grupo A

Nunca percebi diferença nelas.(Lea, 15 anos)

Borboleta é leve e mariposa é mais felpuda. (Mônica, 21 anos)

Borboleta é delicada. (Leo, 12 anos)

São insetos / borboleta é menor que mariposa.(Dani, 18 anos)

Elas diferenciam no tamanho / mariposa é maior, borboleta é mais colorida.(Carla, 36 anos) 


\section{Grupo B}

A lagarta vira casulo que vira borboleta. (João, 9 anos)

Mariposa é mais doméstica, borboleta é mais selvagem é encontrada mais em florestas, parques e zoológicos /Do que elas se alimentam? [pergunta de João para Paulo]

Borboleta é colorida.(Pedro, 5 anos)

Grupo C

Acho que são a mesma coisa / são da mesma família.(Ronaldo, 40 anos)

É tudo a mesma coisa / não sei nem o que é mariposa direito!(Mia, 10 anos)

Grupo D

As bruxas são bem mais diferentes das borboletas, são mais feias.(Alice, 12 anos)

Borboleta é uma lagarta que passa por estágios. (Núbia, 20 anos)

As borboletas são menores que as bruxas. (Cleo, 12 anos)

Os entrevistados utilizam aspectos morfológicos, estéticos, reprodutivos e comportamentais para estabelecerem diferenças entre borboletas e mariposas. No Grupo $A$, Mônica relaciona a quantidade de "felpas" (de fato escamas) presentes no corpo de tais insetos, supondo que por ser a mariposa mais "felpuda" ela é mais pesada que a borboleta. Leo define borboleta como sendo "delicada" e Dani as classifica como sendo "insetos" e estabelece parâmetros ao distinguir borboleta de mariposa pelo tamanho, ao afirmar que a primeira é menor que a segunda. Carla também refere-se ao tamanho entre os dois insetos para diferenciá-los, assim como ao aspecto estético ao dizer que a "borboleta é mais colorida".

No Grupo B, podemos dizer que João aplica o pensamento mágico para explicar a metamorfose da borboleta; Paulo diferencia os dois insetos quanto à preferência de habitat quando diz que mariposa "é mais doméstica" provavelmente refere-se ao hábito desse inseto de freqüentar ambientes iluminados à noite, principalmente residências; Pedro expõe com naturalidade a sua experiência, demonstrando que o aspecto mais marcante para ela numa borboleta é o seu colorido.

Similaridade é o que resume as respostas, tanto de Ronaldo, quanto de Mia do Grupo C, com relação a borboletas e mariposas; Ronaldo arrisca classificá-las presumindo que sejam da "mesma família".

No Grupo $D$ o aspecto estético mais uma vez é citado por Alice que é enfática quando fala da aparência pouco atrativa da mariposa, enquanto que Núbia utiliza o aspecto reprodutivo e Cléo o morfológico ao diferenciar os insetos.

As falas dos grupos familiares, coletadas durante a entrevista, nos auxiliam a identificar a possibilidade de interatividade reflexiva. Indícios da interatividade comtemplativa e direta são explicitadas na observação do comportamento dos grupos no borboletário.

Duas planilhas foram utilizadas para o registro da interatividade entre os membros das famílias e os componentes do borboletário: cartazes, terrários e alguns espécimes. A Planilha 1 registra as observações feitas no auditório do borboletário durante a exposição oral do monitor. Nesse cenário, chama à atenção a pequena interatividade direta entre os visitantes observados e dois dos componentes presentes no auditório: os cartazes e os terrários. Quatro cartazes são afixados a uma das paredes internas do auditório. Esses cartazes possuem ilustrações 
coloridas (fotos e desenhos) e textos que resumem a biologia dos lepdópteros (características morfológicas, comportamentais, reprodutivas ) em dimensões razoáveis para se chamar a atenção num primeiro momento. Somente um cartaz- TROCANDO OS PÉS PELAS ASAS... "Levante e veja em que me transformei." permite ao visitante uma interatividade direta. Ele é composto de doze pares de fotografias coloridas e sobrepostas com espécies variadas de lepdópteros. A fotografia superior mostra a larva e uma pequena legenda - "LEVANTE" - expõe a imagem digitalizada do lepdóptero adulto, identificado pelo nome científico, correspondente à larva do espécime mostrada.

Nenhum dos membros das famílias observadas se dirigiu ou questionou o monitor sobre o conteúdo dos cartazes expostos no auditório. Durante a exposição oral, o monitor utilizou espécimes vivos (larvas), fixados (lepdópteros adultos), ovos e pupas permitindo que as pessoas os tocassem, o que atraía muito a atenção do público às suas explicações. Esta manipulação com o material, ainda que tênue, mostra uma forma de interatividade direta.

Três terrários vazam a parede externa do borboletário próximo a porta de entrada. É possível a visualização de ovos, larvas, pupas e adultos recém eclodidos de borboletas e mariposas através de suas paredes de vidro, tanto do lado externo, quanto do lado interno do auditório do borboletário. Esses terrários foram observados pelas famílias (interatividade contemplativa) enquanto estas ainda estavam do lado de fora do borboletário (antes de serem convidadas à participarem da pesquisa). Já dentro do auditório, foi observada apenas uma interatividade contemplativa de um adulto e um adolescente do Grupo $A$, os quais deram apenas uma olhada rápida nos terrários sem qualquer comentário. Todos os outros grupos familiares observados, dirigiram-se imediatamente às cadeiras para ouvirem as informações dadas pelo monitor. O interesse do público, diante das informações prestadas pelo monitor, crescia à medida que este apresentava e convidava o público a interagir com elementos vivos (ovos, pupas e larvas). Era permitido às pessoas terem em suas mãos esses elementos, os quais causavam tanto admiração quanto espanto. Algumas pessoas demonstraram repugnância aos exemplares expostos; às vezes negavam-se a interagir com os mesmos. Entretanto, esta interatividade direta dos visitantes observados com os elementos vivos gerou conversas inaudíveis entre os membros das famílias e entre esses e o monitor.

A Planilha 2 descreve a visita dos grupos dentro do viveiro observando as borboletas, assim como, a relação dos familiares com o monitor naquele momento. No viveiro ficam expostos apenas espécimes adultos de borboletas, pois sua estrutura é apropriada para insetos de hábitos diurnos enquanto que suas larvas são criadas no laboratório anexo. Não são vistas mariposas adultas, pois estas possuem hábitos noturnos sendo possível vê-las apenas nos terrários protegidos no interior do borboletário. A observação dos grupos familiares no viveiro, revela um aumento da interatividade direta entre os visitantes e os elementos do recinto. Podemos supor que este aumento levou os visitantes a procurarem mais informações com o monitor, pois recorriam a este com certa freqüência para tirar dúvidas e pedir maiores explicações sobre os animais ali expostos. Muitos membros das famílias pesquisadas preferiam observar as borboletas em silêncio, outros observavam e discutiam entre si o comportamento desses animais no viveiro fazendo conexões com o comportamento observado dos mesmos em 
liberdade, incluindo até comparações com outras espécies de insetos. A seguir, é apresentada a transcrição de algumas conversas no viveiro que puderam ser registradas:

Grupo B

Pai, parece com o mosquito da dengue. Olha o olho dele! (Lia, 9 anos)

Será que são da mesma família? Tem nome científico diferente. (Paulo, 39 anos)

Ela tá na água! (Ana, 5 anos)

Grupo D

Essa daqui é a coruja! (Edir, 12 anos)

É a mesma coisa de você tá encostando numa flor! (Cleo, 12 anos)

No quadro I (ver pág. 16 ), resumimos o resultado da observação dos quatro grupos familiares em função do cenário. Definimos como de baixo índice de interatividade ( $\downarrow$ ) os elementos do cenário diante dos quais foram registrados menos de cinco ocorrências de comportamentos interativos. Ao contrário, um alto índice de interatividade ( $\uparrow$ ) registra a ocorrência maior que cinco, isto é, mais de um membro de cada grupo interagiu efetivamente com o elemento do cenário.

A interação social entre visitantes pode ser tão importante quanto ao índice de interatividade presente em uma exposição. O visitante é portador de uma gama de saberes que envolvem associações, comparações e descrições de eventos presentes e passados suscitados pelos componentes do objeto de exposição. As conversas espontâneas captadas no interior dos grupos, demonstraram como a interação social permite o compartilhamento do saberes e talvez possa ser um indício de interatividade reflexiva. Infelizmente nosso instrumento de coleta de dados não possui elementos para análise desse discurso.

\section{5 - CONSIDERAÇÕES FINAIS}

O objetivo de nossa pesquisa é compreender os diferentes níveis de interatividade entre os membros de um grupo familiar e os elementos que compõem dois cenários do borboletário. No auditório, durante a exposição oral, a interatividade contemplativa e direta foi mediada pelo monitor. Segundo Borum (et al, 1995) o comportamento atencioso, tal como observamos nesse cenário, seguido de questionamento e explicação pode ser associado à interatividade reflexiva. A pesquisadora conclui que o compartilhamento de informações, valores e experiências no interior do grupo familiar enriquece sua cultura científica.

Consideramos que a interatividade valoriza a dimensão educativa do espaço não escolar sendo por isso necessário um claro planejamento de níveis - contemplativo, direto e reflexivo - a serem explorados. Ela exige reciprocidade entre o objeto e o visitante na forma da solicitação de informações e de ação. Os elementos do cenário precisam ser suficientemente ricos para possibilitarem múltiplas leituras e significações do objeto sem contudo ultrapassa-lo.

Ao contrário do que ocorreu no auditório, no viveiro a interatividade entre os visitantes e o objeto exposto foram menos mediadas pelo monitor. A exposição oral antecedente permitiu 
aos visitantes re-investirem as informações obtidas. Essas informações induziram os visitantes a observarem mais atentamente as características e comportamento das borboletas, possibilitando conexões com outras informações e saberes. Estas conexões são detectadas nas conversações familiares e demonstram a presença de associações e comparações com eventos e fenômenos cotidianos. No viveiro observamos um maior número de interatividade direta principalmente com os espécimes adultos de borboletas. A função do monitor foi de fornecer mais explicações e discutir outros aspectos relacionados aos insetos.

A entrevista estruturada demonstra o interesse e a curiosidade dessas famílias pelas borboletas e indícios de que o conhecimento escolar é utilizado pelos visitantes como estruturador das respostas. Está evidente nas respostas dos quatro grupos familiares que 0 interesse pelo borboletário ultrapassa os aspectos estéticos apreciativos da beleza e do encantamento dos lepdópteros. Estes visitantes esperam encontrar respostas às suas dúvidas e parecem estar dispostos a uma significativa formação intelectual.

Resta-nos a questão do papel dos zoológicos enquanto possibilidade de construção de um espaço de educação não formal e sua função educativa. $O$ visitante de fim de semana, grupos familiares ou não, buscam de maneira não intencional, uma formação científica complementar. Os cenários propostos pelo zoológico necessitam ser reavaliados segundo uma concepção de ferramentas sócio-culturais de mediação de saberes. A interatividade é um dos aspectos importantes que compõem esta nova visão do museu aberto. Nossa pesquisa apenas começa a propor elementos para auxiliar na busca de parâmetros de análise da função educativa dos espaços não escolares. 
Tabela 1 - Dados sobre a composição dos grupos familiares observados.

\begin{tabular}{|c|c|c|c|c|}
\hline Grupo & № de Participantes & Sexo & Idade & Escolaridade \\
\hline \multirow{5}{*}{$A$} & \multirow{5}{*}{05} & $\mathrm{~F}$ & 15 & EM \\
\hline & & $\mathrm{F}$ & 18 & EM \\
\hline & & $\mathrm{F}$ & 36 & ES \\
\hline & & $M$ & 12 & EF \\
\hline & & $\mathrm{F}$ & 21 & EM \\
\hline \multirow{3}{*}{ B } & \multirow{3}{*}{03} & $\mathrm{M}$ & 9 & $\mathrm{EF}$ \\
\hline & & M & 39 & ES \\
\hline & & $M$ & 5 & $\mathrm{El}$ \\
\hline \multirow{2}{*}{$\mathrm{C}$} & \multirow{2}{*}{02} & $\mathrm{~F}$ & 10 & EF \\
\hline & & M & 40 & EM \\
\hline \multirow{4}{*}{$\mathrm{D}$} & \multirow{4}{*}{04} & $\mathrm{~F}$ & 11 & EF \\
\hline & & $\mathrm{F}$ & 12 & EF \\
\hline & & $\mathrm{F}$ & 20 & EM \\
\hline & & $\mathrm{F}$ & 12 & EF \\
\hline
\end{tabular}

Legenda:

Sexo: $F$ (feminino),

M (Masculino)

Escolaridade: EF (Ensino Fundamental),

El (Educação Infantil),

EM (Ensino Médio),

ES (Ensino Superior)

Quadro I: Índice de interatividade

\begin{tabular}{|l|l|l|l|l|}
\hline \multirow{2}{*}{$\begin{array}{c}\text { Cenário } \\
\text { Interatividade }\end{array}$} & \multicolumn{3}{c|}{ Auditório } & Viveiro \\
\cline { 2 - 5 } & Cartazes & Terrários & Insetos & Insetos \\
\hline Contemplativa & $\uparrow$ & $\uparrow$ & $\uparrow$ & $\uparrow$ \\
\hline Direta & $\downarrow$ & $\downarrow$ & $\uparrow$ & $\uparrow$ \\
\hline Reflexiva & $\mathrm{N}$ & $\mathrm{N}$ & $\uparrow$ & $\uparrow$ \\
\hline
\end{tabular}

Legenda

Alto índice de interatividade: $\uparrow$

Baixo índice de interatividade: $\downarrow$

N: não observado 


\section{REFERÊNCIAS BIBLIOGRÁFICAS}

BORUN, Minda; CHAMBERS, Margareth; CLEGHORN, Ann. Families are learning in science museums. Curator 39/2, June, 1996, p. 123-138

BORUN, Minda; CLEGHORN, Ann; GARFIELD, Caren. Family Learning in Museums: a bibliographic review. Curator 38/4, 1995, p. 262-270.

BORUN, Minda; CHAMBERS, Margareth; CLEGHORN, Ann. Family learning in museums: the PISEC perspective. (traduzido por Cristiana Batista Costa). Philadelphia/Camden Informal Science Education Collaborative (PISEC), Philadelphia, 1998, 67 p.

COSTA, Cristina Batista. A utilização de zoológicos como espaços de educação não-formal : um estudo de caso no borboletário da Fundação Zoobotânica de Belo Horizonte. 2000 Monografia de final de curso. Licenciatura Ciências Biológicas. ICB-FAE-UFMG. Mineo. 34p.

DIERKING, Lynn. D.; FALK, John H. Family behavior and learning in informal science settings: a review of the research. Science Education 78(1):57-72, 1994.

FALCÃO, Douglas. A interatividade nos museus de ciências. Encontro Ciência pop. Rio de Janeiro.2001.

FUNDAÇÃO ZOOBOTÂNICA DE BELO HORIZONTE. Melhorias em infra-estrutura. [online] Disponível na Internet via WWW. URL: http://belohorizonte.mg.br/siga/zoobotanica/index.htm. Arquivo capturado em 30 de junho de 2000.

GUICHARD, Jacques; MARTINAND, Jean-Louis. Médiatique des sciences. PUF: Paris, 2000.

SOCIEDADE DE ZOOLÓGICOS DO BRASIL. Sociedade dos zoológicos do Brasil. [online] Disponível na Internet via WWW. URL: http://szb.org.br/abertura.asp . Arquivo capturado em 30 de junho de 2000.

SOCIEDADE DE ZOOLÓGICOS DO BRASIL. Jardins zoológicos : conservação ex situ da diversidade biológica brasileira. [online] Disponível na Internet via WWW. URL:

http://mma.gov.br/chm/zoo.html. Arquivo capturado em 14 de junho de 2000.

SPEZIALI, Cristiane; VAZ, Arnaldo. O professor e o ensino de ciências no jardim zoológico. Belo Horizonte : UFMG/FAE, 2000.

TUNNICLIFFE, S.D.; LUCAS, Arthur M. School visits to zoos and museuns; a missed educational opportunity? International Journal Science Education, 1997, vol. 19, no 9, p. 10391056. 
VERGNAUD, Gerard. Au fond de l'action, la conceptualisation. In J-M Barbier (Organizador). Savoirs théoriques et savoir d'action. PUF: Paris,1998.

VYGOTSKY, L.S. (1934, 1997). Lev Vygotski Pensé et langage. trad. F. Sève. Pairs, La Dispute.

Data de publicação: 11-03-02

Data de aprovação: 14-03-03 